\title{
Influence of oral contraceptives on the presence and persistence of Candida albicans and $\beta$-haemolytic streptococci in the vagina
}

\author{
C. A. MORRIS \\ From the Public Health Laboratory Service, Bristol
}

SYNOPSIS Samples of vaginal secretions of 'normal' women were examined over a period of up $\stackrel{N}{N}_{-}^{N}$ to two years.

Patients with asymptomatic candidiasis on one occasion were more likely to have Candida albicans

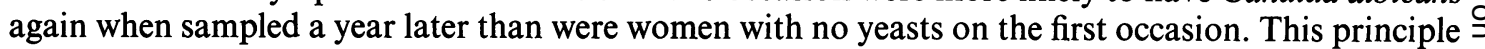
applied also to $\beta$-haemolytic streptococci of Lancefield's groups B and D.

There was no significant difference in the incidence of $C$. albicans in the first and the final samples $\stackrel{\complement}{<}$ collected. The persistence and new infection rates were not significantly higher in patients taking $\vec{\bullet}$ combined oral contraceptives than in other women although the highest incidence occurred in 8 those taking a lynoestrenol/mestranol preparation.

There was a significant association of $C$. albicans with $\beta$-haemolytic streptococci groups B and D. The implication of these findings is discussed.

It has been suggested that oral contraceptives predispose some patients to monilial vulvovaginitis (Walsh, Hildebrandt, and Prystowsky, 1965 and 1968; Yaffee and Grots, 1965; Porter and Lyle, 1966) and this complication may be related to the prolonged use of these drugs (Catterall, 1966).

An attempt to define the extent of this risk was made by studying the vaginal flora of women attending a family planning clinic (Morris and Morris, 1967). In this population women taking oral contraceptives were not significantly more liable to vaginal candidiasis than other patients, but the limited number of observations prevented us from relating these findings to the duration of hormone treatment.

This paper describes further information obtained by examining these same patients after an interval of one and two years.

\section{MATERIAL AND METHODS}

The original population studied was a sequential series of 291 non-pregnant women attending a family planning clinic, most of whom had had one or more pregnancies. One hundred and four of these patients used oral contraceptives at the start of the study and 187 did not. A number of patients who used non-hormonal methods when first examined were subsequently sampled when Received for publication 18 July 1968. using oral contraceptives. A few women stopped taking the pill from personal choice or because they developed a complication. The contraceptive method at the time of sampling is shown in Table $\mathrm{I}$.

The first samples were all collected at the clinic; the later specimens were obtained by visiting the homes of patients living within a 10-mile radius of the clinic. This ? selection of patients favoured the re-examination of those who were originally taking oral contraceptives, since this method is at present more acceptable and accessible to o urban rather than rural dwellers in Wiltshire and Somerset.

To reduce the chance of failing to detect a species when it was present, swabs were collected in triplicate for the first samples and in duplicate for each re-examination.

First samples were inoculated on to media from $N$ charcoal-impregnated swabs in Stuart's thioglycollate transport medium within four hours of collection. Later $N$ samples, collected at evening domiciliary visits, were $\underset{\mathrm{C}}{\mathrm{N}}$ maintained at ambient room temperature overnight in transport medium and the culture plates and enrichment

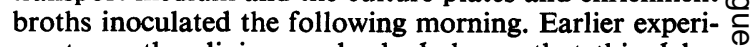
ments on the clinic samples had shown that this delay $\stackrel{\infty}{?}$ before inoculating cultures altered the amount of growth but not the number of isolations of $C$. albicans and $\beta$-haemolytic streptococci.

Candida albicans was isolated by direct plate culture on heated horse blood agar incubated in a candle jar at $\stackrel{\mathbb{D}}{\Omega}$ $37^{\circ} \mathrm{C}$ and by enrichment culture in $3 \%$ glucose broth $\bar{\sigma}$ containing $0.05 \mathrm{mg}$ chloramphenicol per millilitre incubated at room temperature. Plate cultures were $\delta$ 
TABLE I

'NORMAL' WOMEN CLASSIFIED BY CONTRACEPTIVE METHOD AT THE TIME OF SAMPLING

Number of Patients at

First (Clinic) First

Examination
Exal

First

Re-examination

Second

Re-examination Re-sampled

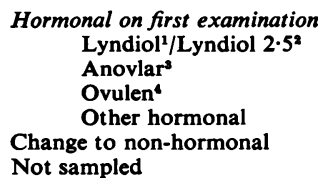

Non-hormonal or no method on first examination Change to

Lyndiol/Lyndiol $2 \cdot 5$

Anovlar

Ovulen

Other hormonal

Not sampled

Total patients sampled

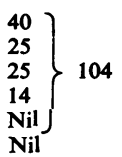

$\left.\begin{array}{r}32 \\ 18 \\ 20 \\ 6 \\ 3 \\ 25\end{array}\right\}$

79

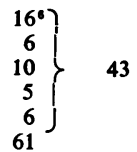

80

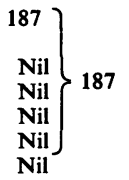

291

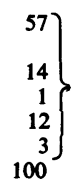

100

\}

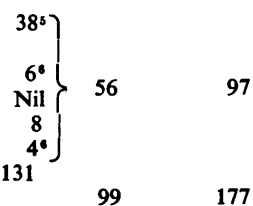

166

${ }^{1}$ Lyndiol, $5 \mathrm{mg}$ Lynoestrenol $+0 \cdot 15$ mestranol (manufacture withdrawn after preliminary sampling and replaced by Lyndiol 2.5 ).

${ }^{2}$ Lyndiol $2.5,2.5 \mathrm{mg}$ lynoestrenol $+0.075 \mathrm{mg}$ mestranol.

${ }^{3}$ Anovlar, $4 \mathrm{mg}$ norethisterone acetate $+0.05 \mathrm{mg}$ ethinyloestradiol.

'Ovulen, $1 \mathrm{mg}$ ethynodiol diacetate $+0.1 \mathrm{mg}$ mestranol

${ }^{3}$ Eight patients re-sampled after two years only.

'One patient re-sampled after two years only.

maintained for 72 hours and broth cultures for seven days.

Beta-haemolytic streptococci were isolated by direct plate culture on $10 \%$ oxalated horse blood agar and on $1 / 300,000$ crystal violet in horse blood agar incubated anaerobically at $37^{\circ} \mathrm{C}$ for 18 to 24 hours. Each strain was examined for its ability to hydrolyse aesculin and the Lancefield's serological group determined using the formamide method for extracting the group-specific polysaccharide (Fuller, 1938).

The selection of the original population studied, the methods of sampling and examining vaginal secretions, and the media used are described more fully in the earlier report.

In analysing the results particular regard was taken of two factors. First, in assessing the proportion of patients infected with yeasts or streptococci, the results of 'the last sample collected' have been considered. It is not valid to summate total isolations from total samples since this might bias the results when there are unequal numbers of samples from different patients. Second, when the persistence of $C$. albicans is considered samples have been included only when patients have remained consistently on the same contraceptive method between two sampling times.

\section{RESULTS}

Further samples were collected from 177 of 291 patients originally examined. One hundred and sixtysix women were examined after one year and 99 after two years; this last group included 11 patients who were not sampled one year earlier.

Among the patients who could not be reexamined on one or more occasions, there were 17 who refused, 16 who became pregnant, 30 who did not reply to the domiciliary visit request letter, and 60 who moved away.

On enquiry, no patient gave a history of diabetes and this condition had not been diagnosed on urine analysis during her last preguancy. Urine and blood sugar levels were not determined in the course of this study.

Samples were not all collected at the same point of the menstrual cycle but the isolation rates of C. albicans did not vary significantly with the day of sampling.

INCIDENCE OF C. ALBICANS There was no significant difference in the incidence of $C$. albicans in first and final samples. Of 291 original samples, $10.7 \%$ contained C. albicans compared with $11.3 \%$ of 255 final samples from patients with no change in their contraceptive method since the previous examination.

Isolations from first and final samples were $13.5 \%$ (104 women) and 13.7\% (102 women) from women taking oral contraceptives and $9 \cdot 1 \%$ and $9.8 \%$ from those using alternative methods.

\section{TABLE II}

INCIDENCE OF $C$. albicans IN RELATION TO CONTRACEPTIVE METHOD

\begin{tabular}{|c|c|c|c|}
\hline \multirow[t]{2}{*}{ C. albicans } & \multicolumn{3}{|c|}{ No. of Patients Using Contraceptive Method } \\
\hline & Non-oral & Oral & Total \\
\hline $\begin{array}{l}\text { Isolated } \\
\text { Not isolated } \\
\text { Total patients }\end{array}$ & $\begin{array}{r}15 \\
138 \\
153\end{array}$ & $\begin{array}{r}14 \\
88 \\
102\end{array}$ & $\begin{array}{r}29 \\
226 \\
255\end{array}$ \\
\hline
\end{tabular}


Patients in this series using oral contraceptives were not significantly $\left(\chi^{2}=0.93\right)$ more liable to vaginal candidiasis than other women even after prolonged use of these drugs (Table II).

PERSISTENCE OF C. ALBICANS Patients with $C$. albicans on first sampling were significantly more likely to have this organism present in samples collected a year later than were women with no yeasts on the first occasion (Table III).

TABLE III

PERSISTENCE OF ASYMPTOMATIC VAGINAL CANDIDIASIS OVER 12-MONTH INTERVAL

$\frac{\text { First Examination }}{\text { Candida albicans }}$ Totals

Second Examination

\begin{tabular}{lrll}
\hline C. albicans isolated & 8 & 16 & 24 \\
C. albicans not isolated & 17 & 169 & 186 \\
Totals & 25 & 185 & $210^{1}$ \\
Exact probability & & $P=0.003$ &
\end{tabular}

'Samples from patients with no change of contraceptive method between examinations.

This tendency of patients to retain candida in the vagina for a period exceeding a year was, however, no greater among patients taking oral contraceptives than among other women (Table IV). The highest incidence occurred in a small group of patients taking Lyndiol/Lyndiol 2.5, the most oestrogenic of the preparations considered here. This incidence was not significantly higher than in other women $(P=0.06)$, but suggests that some preparations may contribute to the development of vaginal candidiasis, a factor which may be confirmed only by studying a larger population.

PRESENCE AND PERSISTENCE OF $\beta$-HAEMOLYTIC STREPTOCOCCI Of the 291 first samples, $10.9 \%$ contained $\beta$-haemolytic streptococci, most of these
(9.6\% of first samples) belonging to Lancefield's $\frac{\text { o }}{\vec{\sigma}}$ groups B or D (op. cit).

From a total of 556 samples collected, 65 yielded $\vec{F}$ $\beta$-haemolytic streptococci. These belonged to the following serological groups (number of strains in brackets): $A(1), \mathrm{B}(35), \mathrm{C}(4), \mathrm{D}(22), \mathrm{F}(1), \mathrm{G}(2)$. Patients with $\beta$-haemolytic streptococci on one $\mathbb{\otimes}$ occasion are significantly more likely to have these in the vagina a year later than are women who have ${ }^{\text {c }}$ no streptococci on first sampling (Table V).

TABLE V

PERSISTENCE OF $\beta$-HAEMOLYTIC STREPTOCOCCI IN THE 'NORMAL' VAGINA OVER 12-MONTH PERIOD

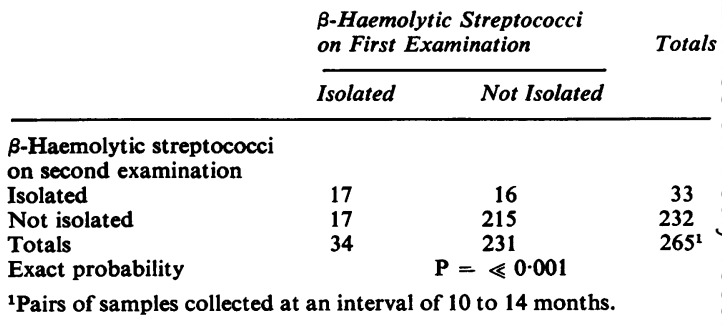

ASSOCIATION OF $\beta$-HAEMOLYTIC STREPTOCOCCI AND C. ALBICANS There is a significant association between the presence of $\beta$-haemolytic streptococcio groups $\mathrm{B}$ and $\mathrm{D}$ and $C$. albicans in the vagina $\frac{\mathrm{Q}}{\mathrm{a}}$ (Table VI).

TREATED VAGINAL DISCHARGES IN THE COURSE OF THIS STUDY Nine patients, three of whom used oral contraceptives and six of whom did not, were? treated by their general practitioner for a vaginal discharge. No microbiological cause was deter- - mined, either before or after treatment in five 3 patients. Trichomoniasis occurred in two women, one in association with $C$. albicans. Two other patients, both using oral contraceptives, had C. albicans after treatment, one patient having been diagnosed before she developed a discharge.

TABLE IV

PERSISTENCE AND NEW INFECTION RATE OF C. ALBICANS IN THE VAGINA IN RELATION TO CONTRACEPTIVE METHOD

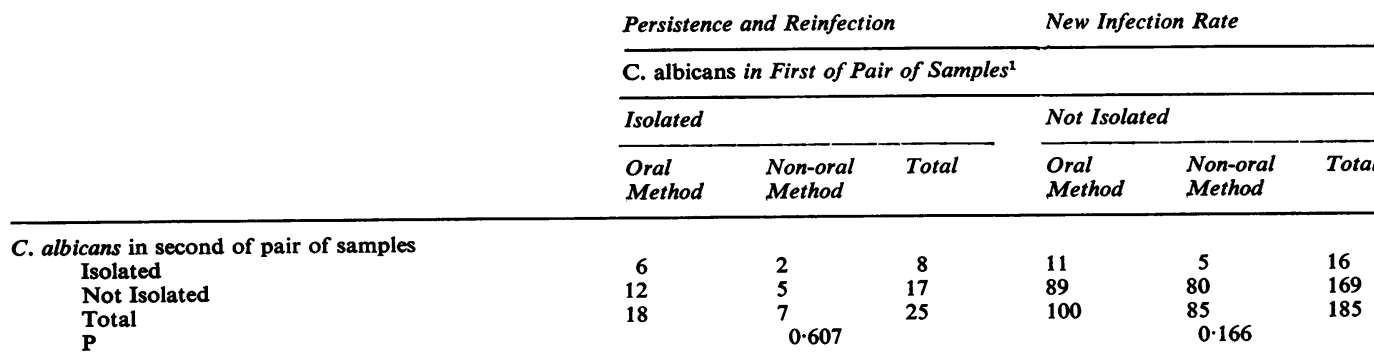

210 patients with samples collected at an interval of 10 to 14 months. 
TABLE VI

ASSOCIATION OF $\beta$-HAEMOLYTIC STREPTOCOCCI AND $C$. albicans IN THE 'NORMAL' VAGINA

\begin{tabular}{|c|c|c|c|c|c|c|}
\hline \multirow{3}{*}{$\begin{array}{l}\text { Candida } \\
\text { albicans }\end{array}$} & \multicolumn{6}{|c|}{$\beta$-Haemolytic Streptococci } \\
\hline & \multicolumn{2}{|c|}{$\begin{array}{l}\text { Lancefield's Group } \\
A, B, C, D, F \text {, and } G\end{array}$} & \multirow{2}{*}{$\begin{array}{c}\text { Total } \\
- \text { Samples }\end{array}$} & \multicolumn{2}{|c|}{$\begin{array}{l}\text { Lancefield's Group } \\
B \text { and } D\end{array}$} & \multirow{2}{*}{$\begin{array}{l}\text { Total } \\
\text {-Sample }\end{array}$} \\
\hline & Isolated & Not Isolated & & Isolated & Not Isolated & \\
\hline $\begin{array}{l}\text { Isolated } \\
\text { Not isolated } \\
\text { Total samples } \\
\text { Exact probability }\end{array}$ & $\begin{array}{r}9 \\
22 \\
31\end{array}$ & $\begin{array}{r}23 \\
237 \\
260 \\
P=0.003\end{array}$ & $\begin{array}{c}32 \\
259 \\
291^{1}\end{array}$ & $\begin{array}{r}9 \\
18 \\
27\end{array}$ & $\begin{array}{r}23 \\
241 \\
264 \\
P=0.0009\end{array}$ & $\begin{array}{c}32 \\
259 \\
291^{1}\end{array}$ \\
\hline
\end{tabular}

${ }^{1}$ Last samples collected.

\section{DISCUSSION}

The results show that $C$. albicans and $\beta$-haemolytic streptococci groups B and D may be present in the vagina for many months without the patient developing symptoms or signs of infection.

The tendency to carry $C$. albicans in the vagina and the association of yeasts and streptococci in this region probably depend upon physiological and environmental factors largely independent of contraceptive methods.

There is inconclusive evidence to suggest that strongly oestrogenic oral contraceptives may contribute to the establishment of vaginal candidiasis.

This study has included patients taking combined oral contraceptives only and the results are not necessarily relevant to patients using sequential preparations.

When diagnosing monilial vaginitis, a distinction is made between the presence of a few yeast-like fungi common in the normal vagina and that of numerous blastospores and mycelia characteristic of the disease state (Liston and Cruickshank, 1940; Boycott, 1961). The presence of scanty yeasts, if confirmed as $C$. albicans, however, may indicate the patient 'at risk' of developing vaginitis under altered physiological conditions, particularly cyesis and diabetes. The tendency for patients taking combined oral contraceptives to develop vaginal moniliasis would appear from this study not to be significantly higher than that of other women. Porter and Lyle (1966) and Catterall (1966), however, found a more rapid response to treatment of established vaginal moniliasis when patients were taken off the pill.
When a patient has symptomatic monilial vaginitis it may therefore be rational to discontinue prescribing a strongly oestrogenic oral contraceptive temporarily but there seems no reason to treat asymptomatic patients prophylactically.

It has been suggested that streptococci of Lancefield's groups B and D are of no aetiological significance in vaginal discharges in non-pregnant women (Morris and Morris, 1967). Group B streptococci have been associated with fatal endocarditis in pregnancy (Rosenthal and Stone, 1940; Ramsay and Gillespie, 1941) and with meningitis and fulminating pneumonia in the newborn (Rogers, 1968). Steps must be taken to protect patients with cardiac lesions and infants at term from the risk of infection from these organisms.

It is a pleasure to acknowledge the clinical assistance of my wife, Dr Delia Morris, and I am also indebted to Miss E. H. L. Duncan for advice on statistics and Dr H. R. Cayton for helpful criticism of this paper.

\section{REFERENCES}

Boycott, J. A. (1961). Lancet, 1, 1071.

Catterall, R. D. (1966). Ibid, 2, 830.

Fuller, A. T. (1938). Brit. J. exp. Path., 19, 130.

Liston, W. G., and Cruickshank, L. G. (1940). Edinb. med. J., 47, 369.

Morris, C. A., and Morris, D. F. (1967). J. clin. Path., 20, 636

Porter, P. S., and Lyle, J. S. (1966). Arch. Derm., 93, 402.

Ramsay, A. M. and Gillespie, M. (1941). J. Obstet. Gynaec. Brit. Emp., $48,569$.

Rogers, K. B. (1968). Symposium: Infections in the newborn. 81st General Meeting of Association of Clinical Pathologists (unpublished).

Rosenthal, A. H., and Stone, F. M. (1940). J. Amer. med. Ass., $114,840$.

Walsh, H., Hildebrandt, R. J., and Prystowsky, H. (1965). Amer. J. Obstet. Gynec., 93, 904.

$-, \frac{1}{1},-$ (1968) Ibid., 101.991.

Yaffee, H. S., and Grots, I. (1965). New Engl. J. Med., 272, 647. 